\title{
Framework of Understanding Somatological Constructs Relative to the Fit of Apparel
}

\author{
Frederick S. COTTLE*1, Pamela V. ULRICH ${ }^{2}$, Karla P. TEEL ${ }^{2}$ \\ ${ }^{1}$ Middle Tennessee State University, Murfreesboro (TN), USA; \\ ${ }^{2}$ Auburn University, Auburn (AL), USA \\ http://dx.doi.org/10.15221/14.347
}

\begin{abstract}
Past research in the field of somatology (human body measurement) related to the fit of apparel has focused on the current apparel manufacturing process flow. In the current system, three dimensional (3D) body form is converted to one dimensional (1D) sizes and two dimensional (2D) shapes in order to utilize shaping methodology in the conversion of $2 \mathrm{D}$ fabrics into a 3D garment that fit the 3D human body form. The somatological constructs of size, build, shape, and form are often used interchangeably in academia and industry. This treatise intends to clarify definitions and bring deeper meaning to these constructs. This clarity and meaning will be used to develop a framework of understanding to use as a lens to view apparel product development and manufacturing as they relate to the fit of garments to the human body. The framework of understanding has the potential to revolutionize the apparel industry by refocusing development efforts toward a more effective process flow and to change the way the fit of garments is measured and evaluated.
\end{abstract}

Keywords: Form, Somatology, Fit, Body Scanning

\section{Introduction}

Somatology, a branch of physical anthropology, uses measurement and observation to study variations in and classifications of the human body $[1,2,3]$. The term, somatology, is rooted in its parts, soma (or body) and logia (the study of) [3]. Related terms include anthropometry and somatography, both of which focus on human body measurement. Anthropometry is the more frequently used term in the apparel field because it has referred historically to the collection of sizing data that is represented by linear measurements between specific locations on the human body (landmarks) using gradated measuring devices like tape measures $[4,3]$. The development of ready-to-wear industrial sectors in the $19^{\text {th }}$ to $20^{\text {th }}$ centuries precipitated study of the human body in the context of fit [1]. Going beyond linear measurements to achieve an in depth understanding of the human body is vital to producing apparel to fit it. For the study of the body in relation to the fit of apparel, the broader term, somatology, is the most appropriate term as it conceptually encompasses evaluating and classifying dimensions of the human body from more than just a linear perspective.

Research related to somatology commonly applies some or all of the constructs, size, build, shape, and form, but they are not consistently defined (implicitly or explicitly) and applied uniformly across studies. In an age of increasingly sophisticated body measurement technology, inconsistency in understanding and using these constructs may hinder researchers in the somatology field from making new advances in measuring and classifying human bodies in ways that can be applied to apparel product development. A clear understanding of how the constructs, size, build, shape, and form, are defined, measured, and have been used in the literature is necessary to offer a structural framework to the field. The purpose of this treatise is to frame a logical system for a consistent understanding of these somatology constructs that can be applied to the fit of apparel on the human body.

\section{Methodology}

This treatise is built on research methodology known as logical argumentation, which is defined as a systematically rational method to make sense of some aspect of the cosmos [5]. It is a way by which seemingly disparate components can be viewed holistically to conceptualize a coherent system that brings clarity, consistency, and potentially new direction to a field of study. The goal of logical argumentation is a primary logical system that exists at the paradigmatic level of understanding, defining technical terms, identifying relationships between the terms, and providing a framework with a large explanatory scope [5].

* Rick.Cottle@mtsu.edu; 1-615-494-8752; www.mtsu.edu 
Through application of this methodology, the goal herein is to present a conceptually foundational framework (primary logical system) to support somatology research directed towards enhanced understanding and improvement of apparel fit.

\subsection{Human Body Measurement Methods}

To build the conceptual framework, methods used to measure the human body must be understood. Bye et al. categorized these as a) linear, b) multiple probe, and c) body form [6]. The linear method of body measurement uses the distance between two points or landmarks on the body to quantify the size of physical dimensions (lengths, widths, or circumferences) such as hips, thighs, waist, or neck. Landmark identification presents a potential for human error because of the need for agreement on the landmark locations on the body [7]. The multiple probe method combines linear measurements with tools that evaluate the relationship between and description of body contours [6]. By evaluating and describing multiple dimensions (linear measurement and contour) of the human body, researchers can study physical parameters that are more related to garment fit. The body form method of describing the human body relies on surface and volume evaluation rather than numerical descriptions [6]. Body form methods include draping and three dimensional (3D) body scanning. A $3 \mathrm{D}$ body scanner is technologically advanced equipment that combines hardware and software to create a dimensionally accurate digital representation of the human form [6]. Scanning data formats can be described in dimensional terms such as point and length (one dimensional [1D]), surface and shape (two dimensional [2D]), and volume (3D). Table 1 is a list of measurement methods, the tools used for each method, and the resulting data formats used to describe the human body.

Table 1. Methods to Measure the Human Body

\begin{tabular}{|c|c|c|c|c|c|c|}
\hline Metho & & Point & Length & Surface & Shape & Volume \\
\hline \multicolumn{7}{|l|}{ Linear } \\
\hline & Tape Measure & - & $\mathrm{X}$ & - & - & - \\
\hline & Proportional Measures & - & $\mathrm{x}$ & - & - & - \\
\hline & Anthropometer & - & $\mathrm{X}$ & - & - & - \\
\hline & Calipers & - & $\mathrm{x}$ & - & - & - \\
\hline \multicolumn{7}{|c|}{ Multiple Probe } \\
\hline & Complex Anthropometer & $\mathrm{x}$ & $\mathrm{x}$ & - & $\mathrm{x}$ & - \\
\hline & Photography & $\mathrm{X}$ & $\mathrm{X}$ & - & $\mathrm{X}$ & - \\
\hline & Somatography & $\mathrm{x}$ & $x$ & - & $\mathrm{x}$ & - \\
\hline \multicolumn{7}{|c|}{ Body Form } \\
\hline & Draping & - & - & $x$ & $\mathrm{X}$ & - \\
\hline & Body Scanning & $\mathrm{x}$ & $\mathrm{X}$ & $\mathrm{X}$ & $\mathrm{x}$ & $x$ \\
\hline
\end{tabular}

Note. Methods and tools to measure the human body and the resulting data format. Adapted from "Analysis of Body Measurement Systems for Apparel" [6].

Apparel fit researchers have used these three measurement methods to investigate a single body construct or a combination of constructs in analyzing the human body. Different body measurement methods may be used for different body constructs. Because differences among body constructs can be nuanced, research should carefully specify operational definitions.

\subsection{Somatological Constructs}

The somatological constructs of size, build, shape, and form are all related to the fit of apparel. Each construct describes the human body in part or as a whole. They make up the measurable increments that can be used in human body analysis. Clear definitions and an understanding of how the constructs are related are necessary to bring clarity to the field of somatology research. The discussion of each construct in the following sections includes definitions, applications, measurement techniques, and past studies. Following that is a summary view to represent the framework of understanding to offer a perspective for future studies of the human form. 


\subsection{Size}

The size of an object is defined as its physical magnitude, extent, or bulk, or as it's relative or proportionate dimensions as an object [3]. Examples of size are length, height, weight, or girth. Thus, size consists of 1D data that can be measured by the linear, multiple probe, and body form methods of data collection [6]. Body size is the 1D measurement of component body parts. This construct is regularly used in research to build databases applicable to the design of products that interact with the human body. Applied research includes extensive anthropometrical studies intended to inform the fit of apparel items to the human body. Examples of these are the O'Brien and Shelton study of adult women's body measurements and the U.S. Air Force anthropometry survey $[8,9]$.

Early anthropometric studies that focused on developing or improving apparel sizing systems tended to consist of length measures collected using linear methodology. The O'Brien and Shelton (1941) study of women's measurements was one of the first to systematically collect linear body measurement data to be used for sizing apparel [8]. Their data continues to be the foundation for women's apparel sizing today, updated and converted into the Commercial Standard: Voluntary Product Standard CS 215-58 [10]. After the Standard's publication, the military was one of a few entities to affect updates for males and females, as evidenced by the 1976 U.S. Air Force anthropometry survey [9]. Recent anthropometric studies utilizing body scanners (e.g., SizeUSA, Size Europe, Size Mexico, CAESAR, and Size Asia) have built larger body size databases that can be classified by demographic segments such as ethnicity, gender, and geographic location. These studies are currently limited to 1D measures that can be used as apparel sizing information. With the limited information provided by length, width, and circumference measures, it is not possible to develop the deep understanding of three dimensional (3D) body form that is necessary to fully address fit of apparel [6].

\subsubsection{Build}

Build is defined as the mode of structure - the bodily conformation of a person [3]. Body build is the relationship between the linear size measurements of component body parts expressed as ratios or proportions. Examples of how to describe body build with linear data include ratios such as bust-tohip, waist-to-hip and thigh-to-calf, and proportions such as between shoulders, chest, waist, and hip. Graphic somatometry is a multiple-probe technique that uses photography to project a shadow of the human body on a 2D grid, creating a silhouette picture [11]. Douty and Brannon used face forward and side silhouette photographs to study female and male body build and posture (see Figure 1) [11, 1]. Their studies advanced somatographic measurement methods and focused on the constructs of body build and posture by visually classifying body types.

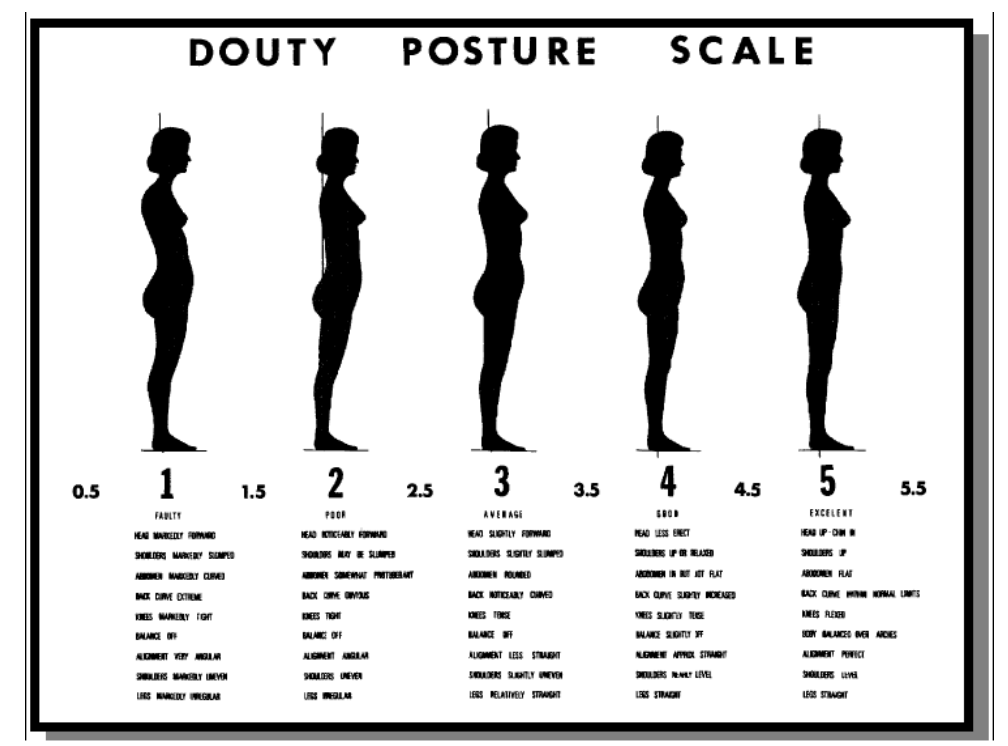

Fig. 1. Douty's Body Build and Posture Scales. Douty's body build and posture scales were derived through visual analysis of photographs projected onto a Cartesian grid structure for reference [11]. 
Douty, Moore, and Hartford went a step further to provide a perspective for analyzing the human body for fit of apparel [12]. They investigated components such as body build, bust size, body tension, lower back curve, pelvic tilt, knee tension, upper back curve, head position, shoulder slope, global posture quality, and figure impression in female subjects [12]. A limitation of their work was that information gaps occurred when attempting to qualitatively synthesize two or more 2D shapes to represent 3D form [6].

\subsubsection{Shape}

Shape is defined as the visible makeup characteristic of a particular item [3]. Shape is the external surface area or outline that an object is perceived to occupy when viewed from a single perspective or angle. Within the creative sciences (art and design), shape is considered to be a 2D construct [13]. In discussing human bodies, particularly females, common examples of shape terms include triangle, rectangle, pear, apple, and hourglass. Shape can be studied using the multiple probe or body form methods. It has been the focus of much of recent somatological study $[14,15]$.

In 1940, a psychologist at Harvard University published research defining three different human body shapes based on visual analysis and classification of photographs of human male subjects [16]. Sheldon developed the three somatotypes, endomorph (short/fat), mesomorph (lean/muscular), and ectomorph (tall/thin), to link them to various psychological disorders. Examples are shown in Figure 2.

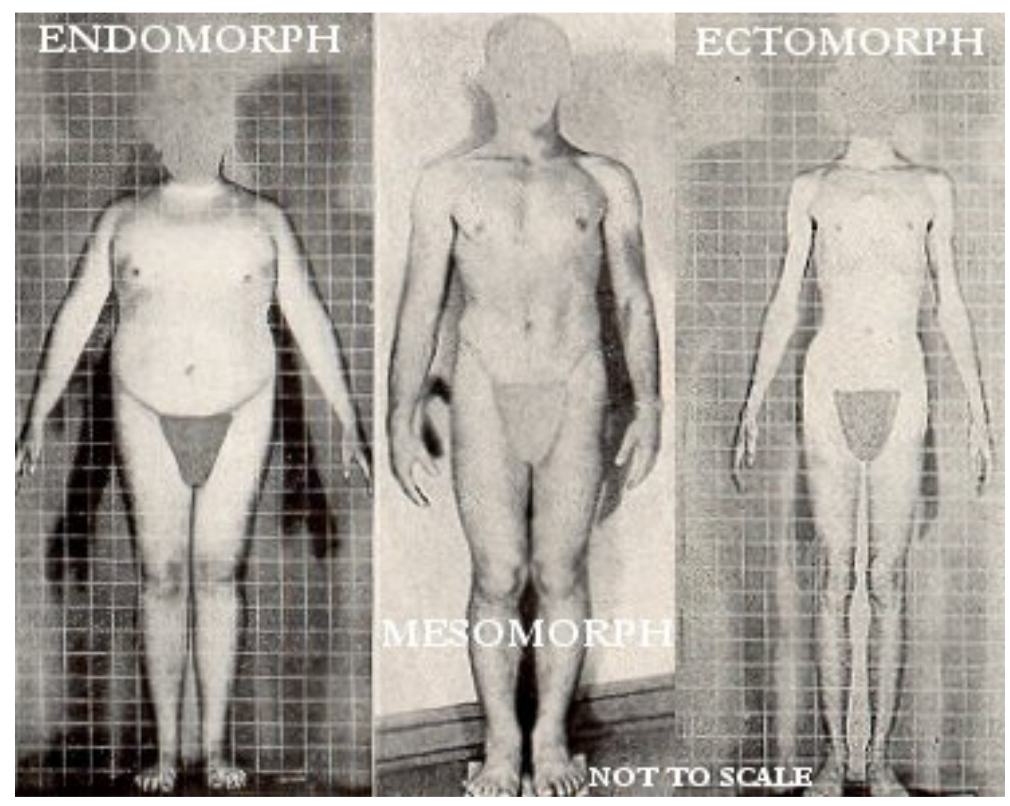

Fig. 2. Sheldon's somatotypes. Sheldon's work is an example of early visual body type classification combining photography with Cartesian grid structure [16].

Sheldon's technique included analyzing photographic images of human male subjects that had been taken from front, side, and back views and then visually synthesizing the 2D shape images into 3D mental representations of body form. Sheldon termed this technique the anthroposcopic or photoscopic method [16]. Sheldon's three somatotypes have received attention over the years as physically descriptive categories of the human body's shape and composition but they were developed with the intent to relate them to psychological disorders. His technique had limitations in that gaps in information can occur when attempting to describe the 3D human body by qualitatively combining two or more 1D size or 2D shape dimensions [6]. Sheldon's methodology was later refined by researchers to better account for the fact that body shape is a continuum and each individual's shape incorporates attributes of all three general somatotype categories [17].

Since Sheldon, the construct, body shape, has been addressed regularly by apparel professionals and scholars in terms of patternmaking, fit, and maximizing a desirable physical appearance. Minott categorized female body shapes as discrete components to be considered in drafting or altering 
apparel patterns to customize them to individual differences $[18,19]$. In developing the Minott Method of fitting patterns, she observed postural characteristics and relationships between shoulders and back blades, as well as waist and hips to describe shape, although the latter relate to the build construct. In each case, when viewed as an outline from one perspective, typically side, front, or back, the impression is of a shape. Armstrong's text on flat patternmaking similarly female body shapes, but considered the shoulder to hip relationship [20]. Her categories of hourglass, straight line, and wide and narrow shoulders may be useful for patternmaking, but are limited to that application.

August classified whole and component parts of female body shapes to offer advice on Looking Thin [21]. All perspectives were either front or side views. She used the shapes of capital letters (A, X, V, and $\mathrm{H}$ ) to designated whole body shapes and lower case letters (b, d, i, and r) for component shapes. Minott's, Armstrong's, and August's investigations were all based on their accumulative, hands-on experience with female body shape, patternmaking, and apparel design $[18,1920,21]$. The Female Figure Identification Technique ${ }^{\odot}\left(\mathrm{FFIT}^{\odot}\right)$, published in 2004, resulted from one of the first studies to utilize 3D body scanning data to classify female body shapes in relation to fit of apparel [15]. This study was an exercise in software development in combination with experts in the field of somatology as related to apparel. Researchers studied 222 female body scans and performed supervised classification of the body shapes. This means that the categories of shape were known a priori, and the subjects were evaluated and placed into those categories [22]. The predefined body shapes were triangle, inverted triangle, rectangle, hourglass, and oval. After the initial evaluation, the five predefined shapes were deemed insufficient to encompass all of the subject shapes in the study, and researchers added four more shape categories; these were termed spoon, diamond, bottom hourglass and top hourglass. Examples of the triangle, rectangle, and hourglass $\mathrm{FFIT}^{\odot}$ shape categories are shown in Figure 3. The ultimate goal of $\mathrm{FFIT}^{\odot}$ for apparel was to define every female shape using the fewest number of categories [15].

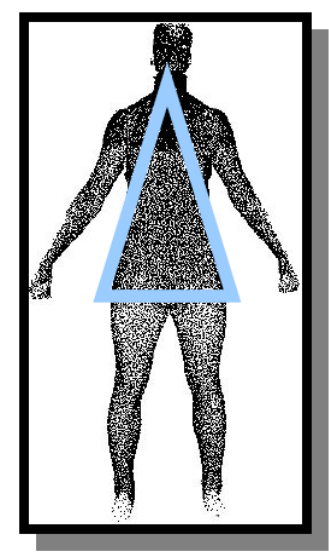

Triangle

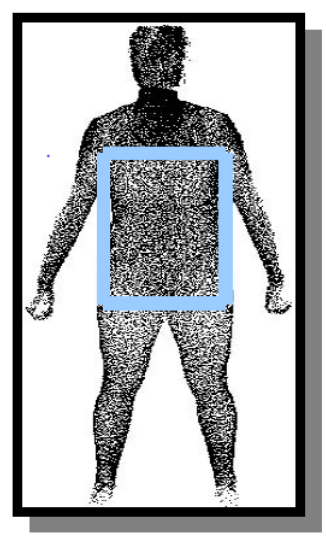

Rectangle

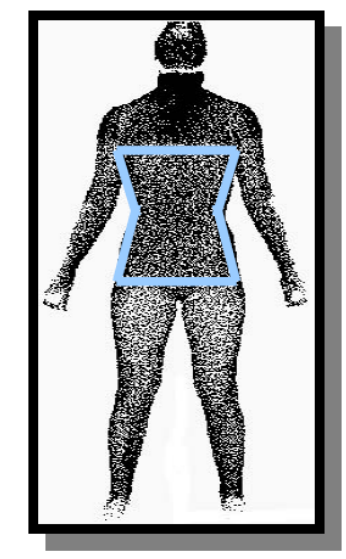

Hourglass

Fig. 3. Female Figure Identification Technique (FFIT ${ }^{\odot}$ ) shape categories. These images are examples of three of the six shape categories identified by the FFIT study in [15].

Additional work in human body shape classification related to apparel included the development of the Body Shape Assessment Scale ${ }^{\odot}\left(\right.$ BSAS $\left.^{\odot}\right)$ [14]. This scale development study was based on quantitative landmark coordinate data derived from 3D body scanning and used expert knowledge to qualitatively classify female body shapes. Like Simmons [15], researchers began with shapes identified in the literature but revised them or defined new classifications. Front and side (2D) images of whole bodies and components of them were printed from 3D body scan data files and visually placed in the synthesized categories. The resulting scale included whole and component part shapes. The nine classifications established were body build, body shape, hip shape, shoulder slope, front torso shape, bust prominence, buttocks shape, back curvature, and posture. Figure 4 is a visual representation of a portion of the $\mathrm{BSAS}^{\odot}$. 


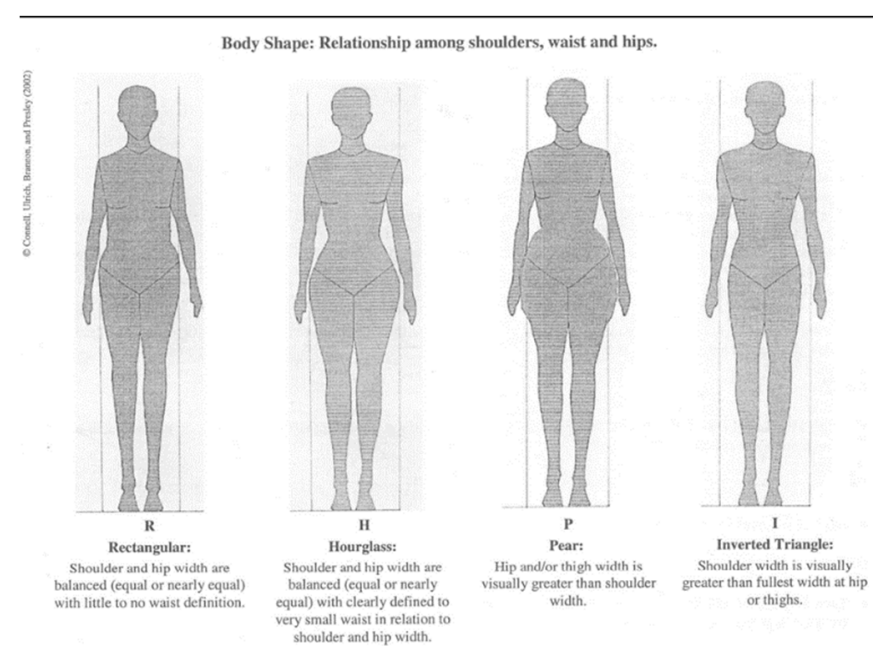

Fig. 4. Body Shape Assessment Scale BSAS ${ }^{\odot}$. These images are shape categories of shoulder, waist, and hip relationships generated from $3 D$ body scan data and visual expert evaluation [14].

Algorithms were then developed in a software program to classify female bodies based on the visually analyzed shape $\mathrm{BSAS}^{\odot}$ categories. Alexander used the BSAS ${ }^{\odot}$ classifications to investigate the relationship of whole and component body shapes with other variables such as age, ethnicity, body build, and posture [23].

The $\mathrm{FFIT}^{\odot}, \mathrm{BSAS}^{\odot}$, and Alexander studies represent the most significant uses of the point cloud data produced by 3D body scanning systems to analyze human body shape with an eye to exploring its relationship to the fit of apparel $[15,14,23]$. However, 2D body shape analysis was the foundation used to place subjects into established shape categories.

\subsubsection{Form}

Although size, build, and shape are vital constructs in the fit of apparel, body form could be considered the quintessential construct to measure, as it best represents all attributes of the actual human body. Form is defined as the structure of something - a human body as distinguished by external appearance [3]. Body form can be operationally defined as the volume that an object occupies in 3D space and is considered to be a 3D construct in the creative sciences (art and design) [13]. One approach to describing body form is suggested by the 3D point cloud data generated in body scans. Analyzing body form can be considered one of the highest order applications for body scanning because the digital data is maintained in $3 \mathrm{D}$ format.

The $\mathrm{FFIT}^{\odot}$ and $\mathrm{BSAS}^{\odot}$ studies used algorithms to analyze 3D body scanning data to classify 2D body shape [24,14]. Although initially these studies visually reviewed 2D computer generated images, ultimately they used algorithms based on 3D form to identify shapes. The somatotyping techniques of Sheldon and Carter-Heath utilized 2D photoscopic methodology to derive an estimate of the form construct [16 17].

Other studies have emerged recently that are intended to analyze the 3D data generated by body scanning. Azouz, Rioux, Shu, and Lepage, developed a methodology to identify contributors to the variation of body form by applying unsupervised classification or clustering techniques to a sample of 300 males [25]. The results of their study revealed five modes of variation; these were height and weight $(33.9 \%$ of variation), posture $(15.1 \%$ of variation), mass distribution and muscularity $(8.9 \%$ of variation), space between arms and torso (4\% of variation), and head position (3.6\% of variation). Normalizing the data for height, weight was found to be the largest contributor to form [25]. Figure 5 shows the results achieved by Azouz et al. where weight becomes the major contributor to body form variation after normalizing the subject data for height. 


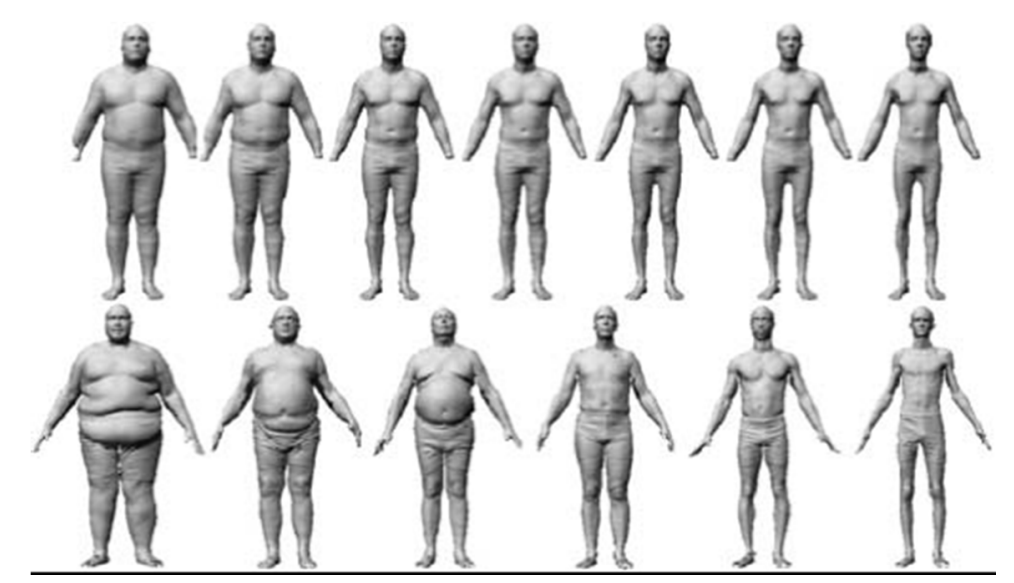

Fig. 5. Body scan images normalized for height. Each subject appears to be the same height while variations in weight become more prevalent. Top images are morphed representations of actual images on bottom row [25].

The study of body form is increasing due to the proliferation of consistent measurement data. Researchers are just beginning to explore the vast potential of the data generated by $3 \mathrm{D}$ scanning. Carter and Stewart suggested that the point cloud related to body form, which is generated by 3D scanning, can be used to generate somatotypes based on the Heath-Carter methodological expansion of Sheldon's techniques [26,16]. However, no logical system currently exists that directly relates the fit of apparel items to the measurement of body form or somatotypes generated by $3 \mathrm{D}$ body scanning. A conceptual framework could add clarity to the field of study and open new avenues of exploration.

\subsection{Conceptual Somatological Framework}

Representing a conceptual framework in tabular form can aid in understanding what is known and what needs to be explored. Table 2 offers a framework for understanding somatological constructs relative to the fit of apparel items to the human body.

Table 2. Framework of Understanding Somatology Constructs Relative to Apparel Fit

\begin{tabular}{|c|c|c|c|c|}
\hline Construct & Size & Build & Shape & Form \\
\hline Dimensionality & 1 & - & 2 & 3 \\
\hline $\begin{array}{l}\text { Measurement } \\
\text { And Evaluation }\end{array}$ & Length & $\begin{array}{l}\text { Waist/Hip } \\
\text { Chest/Waist }\end{array}$ & $\begin{array}{l}\text { Triangle } \\
\text { Rectangle } \\
\text { Pear }\end{array}$ & $\begin{array}{l}\text { Point } \\
\text { Cloud }\end{array}$ \\
\hline
\end{tabular}

$\begin{array}{lllll}\begin{array}{l}\text { Application to } \\ \text { Apparel Fit }\end{array} & \text { 2D Pattern } & \text { 2D Pattern } & \text { 2D Pattern } & \begin{array}{l}\text { Fit Model } \\ \text { Dress Form }\end{array} \\ \text { Study Data Availability } & \text { Yes } & \text { Yes } & \text { Yes } & \text { Limited }\end{array}$

Note. Build consist of ratios of sizes measures resulting in no dimensionality. Two dimensional pattern adjustments based on size, build, and shape measures are currently related to the fit of apparel. Little research exists in the evaluation of 3D body form point cloud data's direct relation to the fit of apparel.

When the constructs are considered in gestalt, it becomes apparent that the apparel industry does not fit sizes, builds, or shapes; the apparel industry's ultimate measure of fit is on the human body (3D) of the customer. The point cloud data generated by 3D body scanning is considered the best available digital representation of the actual human body. The constructs of size, build, and shape are used as measures to derive an estimate of the human body form in order to manipulate 2D fabrics into 3D garments. These are the constructs that have been studied the most in academia. The framework for understanding offered in Table 2 reveals that more resources should be focused on evaluating and understanding the point cloud 3D representation of the human body and its applicability to the fit of apparel. 


\section{Body Form Measurement Relevance to Fit of Apparel}

The current relation of body form measurement to the fit of apparel can be delineated as converting the $3 \mathrm{D}$ point cloud data to $1 \mathrm{D}$ measurements; relating those $1 \mathrm{D}$ measurements to $2 \mathrm{D}$ flat patterns; and then converting the $2 \mathrm{D}$ flat patterns back into $3 \mathrm{D}$ garments to try to fit the $3 \mathrm{D}$ human body. This could be termed the 3D-to-1D-to-2D-to-3D method of apparel fit and is represented in Figure 6.

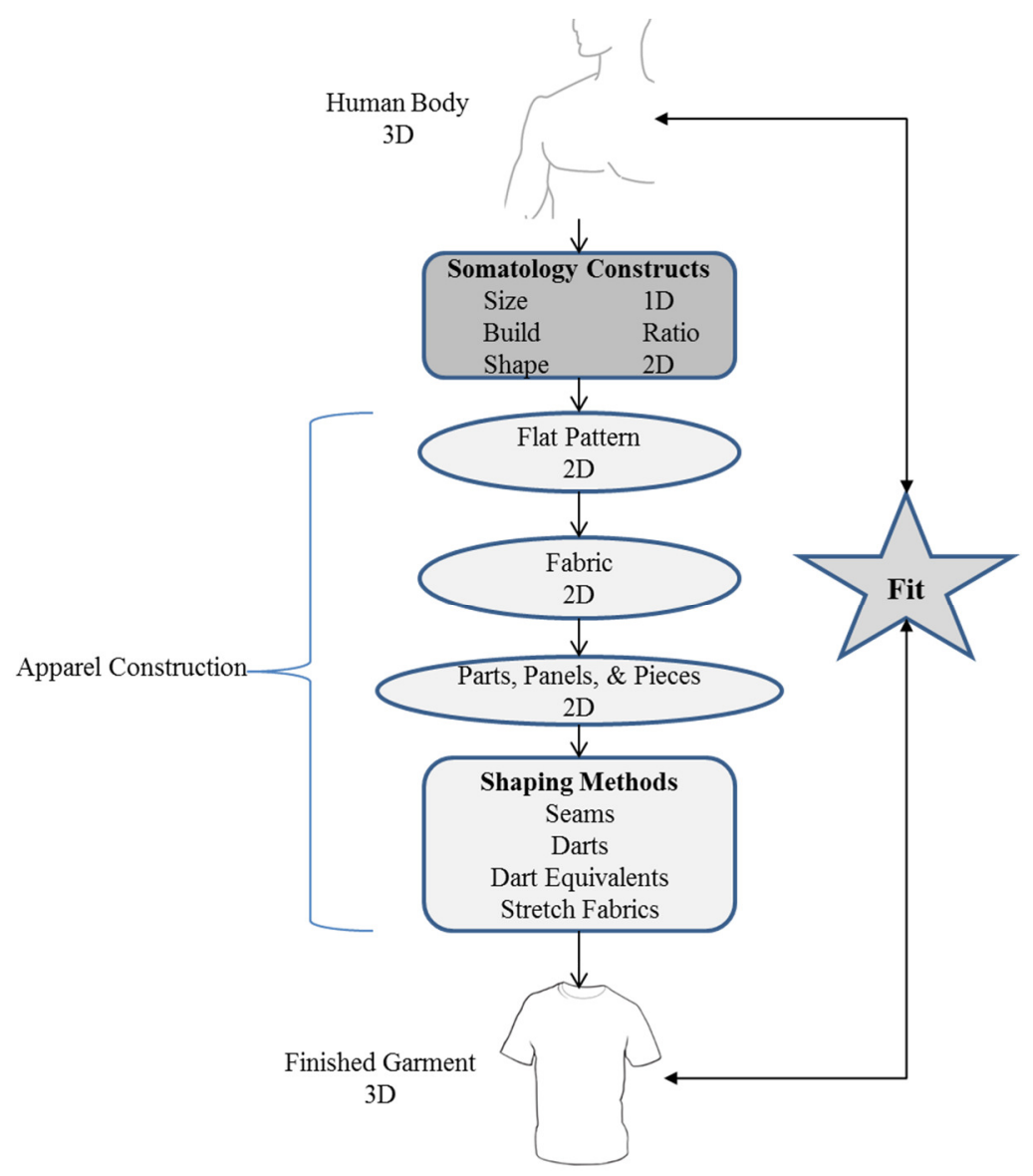

Fig. 6. Current apparel manufacturing process flow related to the fit of finished garments to the human body form.

The established procedure seems to be a less than efficient use of the valuable 3D form data generated by body scanning technology. There are three instances of dimensional data conversion, and each instance results in the loss of data value [6]. This treatise has presented the idea that much past research emphasis has focused on making the 2D flat pattern process more efficient. Should this remain the primary focus of somatological study? If not, a hindering problem is that currently no measurable construct definition of form, relating the 3D point cloud generated by body scanning to the fit of apparel, exists.

\section{Conclusions and Expectations}

An understanding of the conceptual somatological framework presented here has the potential to create a paradigmatic shift in two areas of the apparel industry. One is to shift resources from a focus on improving efficiencies in the current system toward a focus on the development of a more effective system by eliminating the size measurement (1D) to flat pattern (2D) steps in the process. The second is to refocus resources on a new apparel production process flow by developing 3D-to-3D methods related to the production and fit of apparel.

The technology to measure body form has existed for nearly two decades. Evaluating and measuring individual body form has the potential to impact bespoke manufacturing of apparel by using form measurement methodology to provide a better custom fit. Exploration of a means to cluster body 
forms using the high dimensional data generated by 3D body scanning is underway [27]. A methodology to accomplish statistically derived clusters could provide a categorical landscape of body forms that is descriptive of specific samples of the human population. Such advancement has the potential to transform the ready-to-wear market sector by revealing categories of human body forms that particular apparel brands are attempting to fit. Additionally, the apparel manufacturing process flow shown in Figure 7 suggests a conceptual possible future view of the apparel industry. It is an idea that could be explored further by a collaborative effort between textile technologists, polymer engineers, biomechanical engineers, and computer scientists.

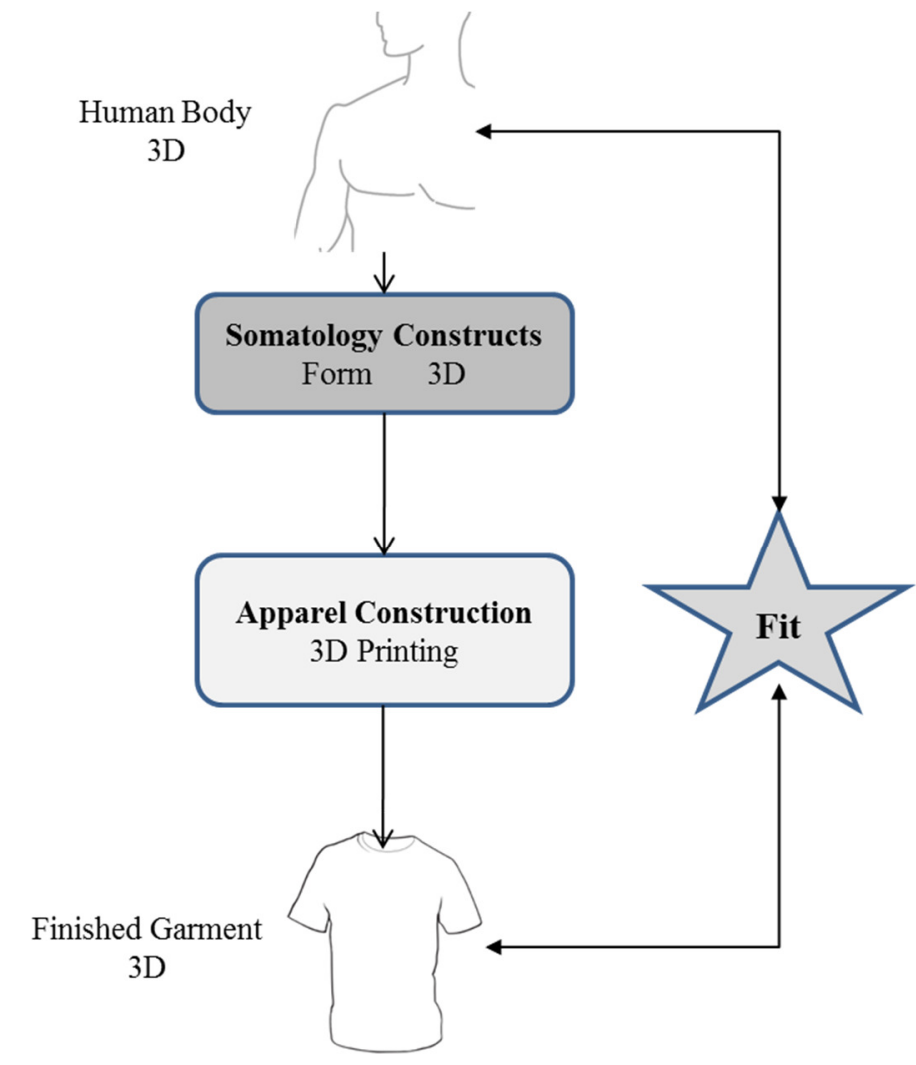

Fig. 7. Conceptual apparel manufacturing process flow related to the fit of finished garments to the human body form.

Understanding the constructs of somatology related to the fit of apparel is a foundational tool that researchers, product developers, and manufacturers could use as a lens to consider the future of the apparel industry. Along with current advancements in 3D printing technology that include hardware, software, and print polymers, this new lens has the potential to revolutionize research in apparel design, manufacturing, marketing, and ultimately improve the fit of apparel items to the actual human body. The next step toward this conceptual future is research aimed at developing an accurate operational definition of body form (based on 3D point cloud measurement) and defining how it relates to the fit of apparel items to the human body. 


\section{References}

[1] E. Brannon, "Graphic somatometry in the development and application of posture and body build scales for men", Unpublished master's thesis, 1971, Auburn Univeristy, Alabama.

[2] Physical Anthropology, In Medilexicon online medical dictionary, n.d., http://www.medilexicon.com/medicaldictionary.php.

[3] Webster's, Webster's third new international dictionary, unabridged: The great library of the English language. Springfield, MA, USA, Merriam, 1993.

[4] C. Kidwell, Cutting a fashionable fit: Dressmakers drafting systems in the United States. Washington, D.C., Smithsonian Institute Press, 1979.

[5] I. Groat and D. Wang, Architectural Research Methods, New York, John Wiley \& Sons, 2002.

[6] E. Bye, et al.,2006. "Analysis of body measurement systems for apparel", in Clothing \& Textiles Research Journal, Vol.24 No.2, 2006. Pp.66-79

[7] S. Lele and J.Richtsmeier, An invariant approach to statistical analysis of shapes, New York, Chapman \& Hall/CRC, 2001.

[8] R. O'Brien and W. Shelton, Women's measurements for garment and pattern construction, Miscellaneous Publication No. 454. Washington, D.C., U.S., Government Printing Office, 1941.

[9] E. Churchill and J. McConville. Sampling and data gathering strategies for future USAF anthropometry (AMRL-TR-74102), Wright-Patterson Air Force Base, OH, Aerospace Medical research Laboratory, Aerospace Medical Division, (AFSC), 1976.

[10]U.S. Department of Commerce, Body measurements for the sizing of women's patterns and apparel (Commercial standard CS215-58), Washington, DC, USA, Government Printing Office, 1958.

[11]H. Douty 1968. "Silhouette photography for the study of visual somatometry and body image", in Proc. of the National Textiles and Clothing Meeting, Minneapolis, Minnesota USA, 1968.

[12] H. Douty et al., "Body characteristics in relation to life adjustment, body-image and attitudes of college females", in Perceptual and Motor Skills, Vol. 39, 1974, pp.499-521.

[13]A. Fiore, Understanding aesthetics for the merchandising and design professional, New York, Fairchild Books, 2010.

[14]L. Connell et al., "Body shape assessment scale: Instrument development for analyzing female figures", in Clothing and Textiles Research Journal, Vol.24, No.2, 2006, pp.80-95.

[15]K. Simmons et al., "Female figure identification technique (FFIT) for apparel. Part I: Describing female shapes", in Journal of Textile and Apparel, Technology and Management, Vol.4, No.1, 2004a, pp.1-16.

[16]W. Sheldon, The varieties of human physique. New York, Harper and Brothers, 1940.

[17] J. Carter and B. Heath, Somatotyping - development and application. Cambridge: Cambridge University Press, 1990.

[18]J. Minott, Pants and skirts ( $2^{\text {nd }}$ edn.). Minnesota, USA, Burgess Publishing Company, 1972, pp. 10-12.

[19]J. Minott, Fitting commercial patterns: The Minott method. Minnesota: Burgess Publishing Company, 1978.

[20] H. Armstrong, Patternmaking for fashion designers. (5 $5^{\text {th }}$ edn.) pp. 35-43, New York, Harper Collins, 1987.

[21]B. August, Complete Bonnie August dress thin system. New York: Rawson, Wade Publishers, Inc., 1981.

[22] L. Costa and R. Cesar. Shape Analysis and Classification: Theory and Practice, New York, CRC Press, 2001.

[23] M Alexander, "Applying three-dimensional body scanning technologies to body shape analysis", Unpublished doctoral dissertation, 2003, Auburn University, Alabama.

[24] K. Simmons et al., 2004b. "Female figure identification technique (FFIT) for apparel. Part II: Development of shape sorting software", in Journal of Textile and Apparel, Technology and Management, Vol.4, No.1, 2004b, pp.1-15.

[25]Z. Azouz et al., 2006. "Characterizing human shape variations using 3D anthropometric data." in Visual Computing, 22, 2006, pp. 302-314.

[26]J. Carter and A. Stewart, 2012. "Physique: phenotype, somatotype and 3D scanning." in A. Stewart and L. Sutton (Eds.), Body Composition in Sport, Exercise and Health, Chapter 4, London, Routledge, 2012.

[27]F. Cottle, 2012. "Statistical human body form classification: Methodology development and application", Unpublished doctoral dissertation, 2012, http://etd.auburn.edu/etd/bitstream/handle/10415/3071/Cottle\%20Dissertation\%202012.PDF?seq uence $=2$. 